\title{
Complications of Delayed Tube Removal after Dacryocystorhinostomy Surgery in the COVID Era
}

\author{
Sthapit PR ${ }^{1 *}$, Manandhar $A^{1}$, Paudel $\mathbf{M}^{1}$, Amatya $\mathbf{M}^{1}$, Saiju $\mathbf{R}^{1}$ \\ ${ }^{1}$ Tilganga Institute of Ophthalmology, Kathmandu, Nepal
}

*Corresponding Author: Purnima Rajkarnikar Sthapit, Department of Oculoplasty and Ocular Oncology, Tilganga Institute of Ophthalmology, Gaushala, Kathmandu, Nepal; Email: purnimark@ gmail.com

Received Date: 10-11-2021; Accepted Date: 10-12-2021; Published Date: 17-12-2021

Copyright $^{\odot} 2021$ by Sthapit PR, et al. All rights reserved. This is an open access article distributed under the terms of the Creative Commons Attribution License, which permits unrestricted use, distribution and reproduction in any medium, provided the original author and source are credited.

\begin{abstract}
Purpose: A silicon stent intubation, done after Dacryocystorhinostomy (DCR) surgery, is generally removed after 6 weeks. However COVID-19 related lockdown as well as recommendation to hold the lacrimal procedures for safety related purpose had led to delay in silicon tube removal for many months. Side effects of even short term silicon stenting are well known. The purpose of this study was to assess the complications of delayed stent removal after DCR surgery, due to COVID restrictions.

Materials and Methods: A cross sectional study that included 35 post DCR patients whose silicon tube removal was delayed due to COVID restrictions, was done. Detail history and clinical examination to note the DCR surgery and tube related complications were noted. Silicon tube was removed and syringing done where possible.

Result: Mean age was 41 years (SD 14.3; range 7-68 years). Among them, 29(83\%) were females. The most common presenting symptom was persistent watering in 19 patients (54.2\%); however syringing was found to be patent in 30 patients (85.7\%). Out of 35 eyes, 26 (74.3\%) had the silicon tube in situ in normal position without puncta or canaliculus complications.

The mean (SD) time of delay in tube removal after DCR surgery was 9.5 (2.9) months. The average (SD) delay time in months of study participants who had complications and without complications were 8.3 (2.7) and 10 (2.8) respectively, which was not statistically significant.
\end{abstract}

Conclusion: Delay in silicon tube removal is a safe practice in COVID era. 


\section{Keywords}

Dacryocystorhinostomy; Silicon Lacrimal Stent; COVID-19; Delayed Tube Removal; Epiphora

\section{Introduction}

Dacryocystorhinostomy (DCR) is the commonest surgery done worldwide for epiphora due to obstruction of the lacrimal drainage system at various levels as well as for functional epiphora. It is done in children who have persistent congenital nasolacrimal duct obstruction after conservative methods have failed. More commonly it is done in adults for blockade of canaliculus or nasolacrimal duct due to chronic dacryocystitis. DCR can be done either via external route (skin incision) or nasal route (endoscopic DCR).

Surgical treatment of dacryocystitis dates back 2000 years ago [1,2]. However the earliest operation that would resemble a present day external DCR was first explained by Woolhouse in England in the $18^{\text {th }}$ century and various modifications were tried by surgeons throughout the globe $[1,3]$. Stenting materials like catgut, gold, silver or glass tubes were used to ensure the patency of the ostium and canaliculus. In the modern day, silicon tube, which was first introduced by Gibbs in 1967, is a preferred material because it is inert, durable, flexible and easy to remove [4,5]. At the end of the DCR surgery, a silicon tube is inserted through both the canaliculus down the nasal cavity to maintain the patency of the newly formed ostium that connects conjunctival cul de sac to the nasal cavity. Depending on the surgeon's preference and other factors, the tube is generally removed after 6 to 12 weeks.

However, this scenario had temporarily been altered in our hospital during the first wave of COVID-19 pandemic. There was a consensual guidance from the AAO (American Academy of Ophthalmology) and AIOS (All India Ophthalmic Society), to avoid any type of lacrimal drainage system surgeries and procedures to avoid the potential danger of spreading Corona virus to healthcare personnel and surrounding people [6,7]. Hence, DCR surgery (both open and endoscopic) as well as silicon tube removal of previously done DCR had been halted since several months. The government-imposed lockdown had also hindered the patients seeking for advice regarding care of tube and its removal.

There are well known adverse effects of silicon tube intubation done even for shorter duration. The aim of this study was to see the complications due to delayed DCR tube removal. There are some case reports of complications due to delayed tube removal. To the best of our knowledge, ours is the first study where we included a large number of patients whose tube removal had been delayed due to unavoidable circumstances. 


\section{Methodology}

This is a cross sectional study done at Oculoplasty and ocular oncology department of Tilganga Institute of Ophthalmology, Kathmandu, Nepal from November 2020 to April 2021. The study adhered to the principles of the declaration of Helsinki and was approved by the Institutional review board. All consecutive post DCR with silicon intubation patients whose surgery was done before the pandemic and who came for delayed tube removal were included in this study. Post DCR without silicon tube and whose tube removal was done within six weeks (as per the practice done at the institute) of surgery were excluded from the study.

A complete history was taken regarding possible complications of prolonged tube placement in eye as well as those related to DCR surgery itself. A thorough ophthalmic examination was done and findings noted. All the study patients had received a silicon bicanalicular rod (solid of $0.64 \mathrm{~mm}$ diameter) intubation. Syringing was performed where possible and tube was removed irrespective of the syringing results. Silicon tube was removed in outpatient department by cutting the tube at the medical canthus. The patient was then asked to blow the nose to retrieve it completely from the nostril. Patient was asked to give an informed consent before enrolling in the study and confidentiality of the data were maintained.

Data entry, cleaning, coding etc. were done in Microsoft Excel. Statistical analysis was done with SPSS software for windows version 20.0. Mean, standard deviation, range and percentage values were calculated as descriptive statistics. For association of categorical data with less than expected count 5, Fisher exact test was used. For continuous numerical data, independent t-test was used. A p-value $<0.05$ was considered statistically significant.

\section{Result}

There were a total of 35 patients with delayed tube removal who were included in the study. All the patients in the study had undergone unilateral DCR with silicon tubing before March 2020 (after which lockdown had begun in Nepal and all the lacrimal procedures were halted till November 2020).

Among the 35 patients, 29 (82.9\%) were females and $6(17.1 \%)$ were males. The mean age of patient at the time of tube removal was 41 years (SD: 14.3, range: 7-68 years) which was 35.3 (SD: 17.5, Range: 13-57 years) in males and 42.2 (SD: 13.6, Range: 7-68 years) in females. The average age of male and female study participants was not statistically significant, $\mathrm{p}=$ 0.288 .

Only nine patients $(25.7 \%)$ were from Kathmandu valley while the rest 26 (74.3\%) patients were from outside the valley which also contributed to the delay in tube removal due to travel restrictions. The next common district was the neighbouring district Kavre (4 patients), while the rest of patients were scattered all over Nepal in 20 districts which is tabulated in Table 1. 
The most common symptom in patients coming for tube out was persistent watering in 19 patients $(54.2 \%)$ followed by discharge from the same eye in 9 patients $(25.7 \%)$; however, on performing syringing, it was found to be patent in 30 patients $(85.7 \%)$. Regurgitation with mucopurulent discharge from opposite punctum was seen in one patient only (2.9\%) and she underwent redo DCR with tubing after eight months of first surgery. Out of remaining four patients, syringing was not done in two in view of pediatric age and the parents were not complaining of watering as well. In two of them, follow up was done by telephone only. Among them, one of them got the tube removed in local hospital but syringing was not done and another patient still had tube in situ without any symptoms and could not travel for tube removal at that moment. Five patients $(14.3 \%)$ did not have any complaints with delayed tube removal. The other presenting symptoms are shown in Fig 1.

Out of 35 patients, $9(25.7 \%)$ had complications and $26(74.3 \%)$ did not have any complications $(\mathrm{p}=0.004)$. Two $(22.2 \%)$ male patients had complications while $4(15.4 \%)$ did not have complications. Gender was not statistically associated with or without having complication $(\mathrm{p}=0.635)$. The overall average (SD) delay time was 9.5 months (SD 2.9, range 1.5-14.8), which was 8.3 months (SD 2.7, range 4-11.5) and 10 months (SD 2.8, range 1.5-14.8) in with and without complication group respectively $(\mathrm{p}=0.122)$. In most of the study participants' $(15$, $42.9 \%$ ) delay time in month was more than 9 to 12 months (Table 2).

In complications, cheese wiring of puncta was seen in 4 patients $(11.4 \%)$, nasal crust in 3 $(8.6 \%)$ and spontaneous tube loss in $2(5.7 \%)$. Rest of the complications are enumerated in Table 3. There were no cases of canaliculitis, interpunctal synechia, granuloma formation on puncta or nasal cavity. Tube removal was successful in clinic in 32 patients (91.4). Remaining three patients had self-extrusion of tube at home.

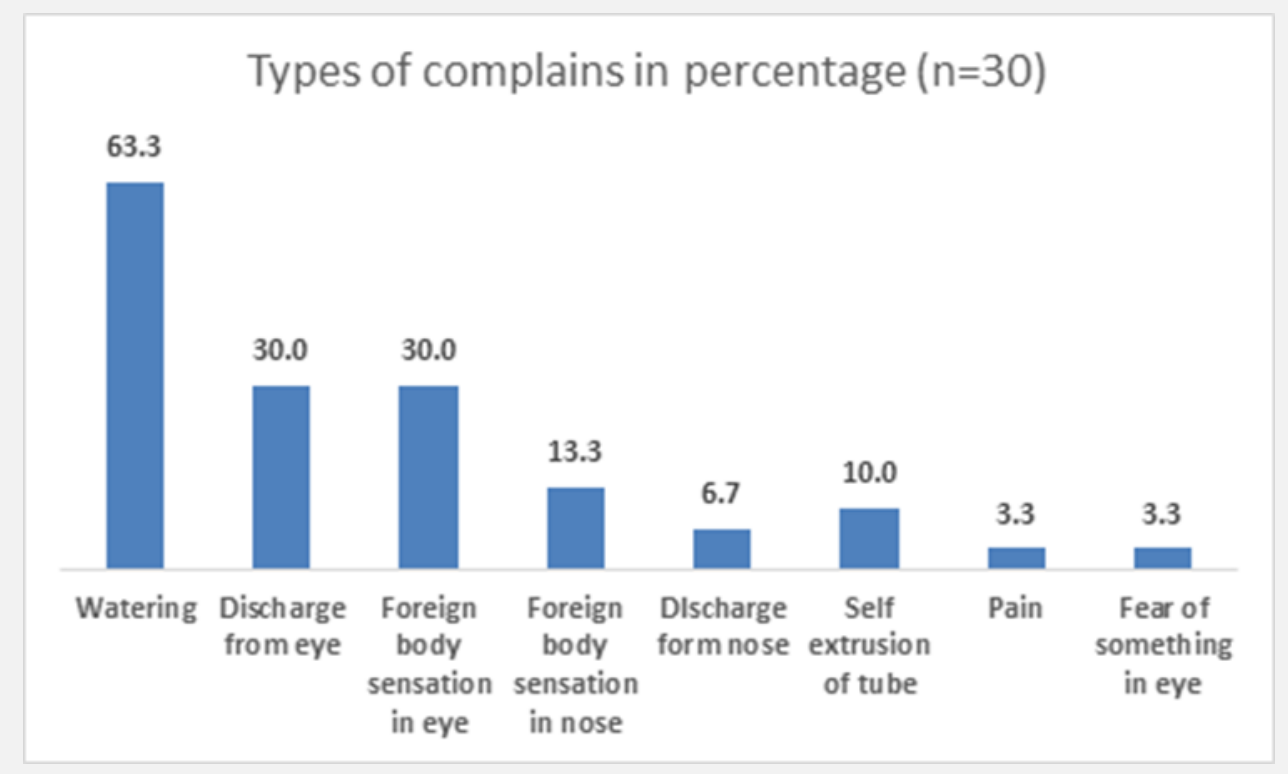

Figure 1: Types of complaints. 


\begin{tabular}{|c|c|}
\hline \multicolumn{2}{|c|}{ Gender } \\
\hline Male, n (\%) & $6(17.1)$ \\
\hline Female, n (\%) & $29(82.9)$ \\
\hline \multicolumn{2}{|c|}{ Age (in years) } \\
\hline Male, average (SD, Range) & $35.3(17.5,13-57)$ \\
\hline Female, average (SD, Range) & $42.2(13.6,7-68)$ \\
\hline Total, average (SD, Range) & $41(14.3,7-68)$ \\
\hline \multicolumn{2}{|c|}{ Place of Residence } \\
\hline KTM Valley, n (\%) & $9(25.7)$ \\
\hline Outside KTM Valley, n (\%) & $26(74.3)$ \\
\hline
\end{tabular}

Table 1: Demographic characteristic of study participants.

\begin{tabular}{|c|c|c|c|c|}
\hline Variables & Total & Complication, No & Complication, Yes & p-value \\
\hline Total, n (\%) & 35 & $26(74.3)$ & $9(25.7)$ & 0.004 \\
\hline \multicolumn{5}{|c|}{ Gender } \\
\hline Male, n (\%) & $6(17.1)$ & $4(66.7)$ & $2(33.3)$ & \multirow[t]{2}{*}{0.635} \\
\hline Female, n (\%) & $29(82.9)$ & $22(75.9)$ & $7(24.1)$ & \\
\hline \multicolumn{5}{|c|}{ Delay time (in months) } \\
\hline Up to $6, \mathrm{n}(\%)$ & $5(14.3)$ & $2(40.0)$ & $3(60.0)$ & \multirow{4}{*}{0.219} \\
\hline$>6-9, \mathrm{n}(\%)$ & $10(28.6)$ & $8(80.0)$ & $2(20.0)$ & \\
\hline$>9-12, \mathrm{n}(\%)$ & $15(42.9)$ & $11(73.3)$ & $4(26.7)$ & \\
\hline$>12, \mathrm{n}(\%)$ & $5(14.3)$ & $5(100.0)$ & $0(0.0)$ & \\
\hline Mean (SD) & $9.5(2.9)$ & $10(2.8)$ & $8.3(2.7)$ & 0.122 \\
\hline
\end{tabular}

Table 2: Association of different variables with or without complication. 


\begin{tabular}{|c|c|}
\hline Complications & n (\% among complications) \\
\hline \multicolumn{2}{|c|}{ Puncta and canaliculus related complications } \\
\hline Punctal stretch & $1(11.1)$ \\
\hline Cheese-wiring of puncta & $4(44.4)$ \\
\hline Cheese-wiring of canaliculus & $1(11.1)$ \\
\hline Granulation formation on puncta & $0(0)$ \\
\hline Interpunctal synechiae & $0(0)$ \\
\hline Canaliculitis & $0(0)$ \\
\hline \multicolumn{2}{|c|}{ Tube related complications } \\
\hline Lateral migration of tube & $1(11.1)$ \\
\hline Corneal erosion & $1(11.1)$ \\
\hline Whitish plaque formation on tube & $1(11.1)$ \\
\hline Tube loss & $2(22.2)$ \\
\hline \multicolumn{2}{|c|}{ Nasal cavity related complication } \\
\hline Nasal crust & $3(33.3)$ \\
\hline Granuloma tissue formation & $0(0)$ \\
\hline
\end{tabular}

Table 3: Complications due to silicon tube in situ for prolonged duration.

\section{Discussion}

Silicon tube is an inert material placed during DCR surgery, for about 2 to 6 weeks. The purpose of this intubation is to prevent failure of DCR surgery from fibrosis and stenosis of mucosal tissue lining along the drainage pathway especially at common canaliculi or at the entrance to nose, because of post-surgical adhesions between sac flaps or between turbinates and ostium [8].

Chronic dacryocystitis is more common in females due to anatomically narrower lacrimal drainage system than in males leading to females coming for DCR more often. In this study as well there were a considerably greater number of female participants (29/6) with p-value of 0.288 , which is consistent with previous studies [9-13]. 
Among the 35 patients in this study with delayed tube removal, 30 patients had some complaints. The most common one being mild persistent watering in $19(63.3 \%)$ with associated mucoid discharge in $9(30 \%)$ patients. However on performing syringing only one patient had regurgitation of mucoid fluid from opposite punctum. Complains of watering could be most likely due to tube related complications like mild infection, plaque formation, corneal erosion due to lateral migration of tube which was seen in our patients or inappropriate size of tubing (tight fitting of tube over puncta and canaliculus).

Lee MJ in a study to evaluate long-term outcomes of maintenance of lacrimal silicone stent after DCR surgery for functional epiphora, found no epiphora and complications once inserted in 18 eyes (34.6\%), whereas tube replacement was needed in 14 eyes $(26.9 \%)$ because of nasal crust or whitish plaque formation on the tube surface. In 13 cases (25.0\%), silicone stent was removed because of tube-related complications, most common being canaliculitis in $15.4 \% .10$

Massoud OM, et al., evaluated the role of silicone intubation in non-complicated external dacryocystorhinostomy. They reported that the patients complaining of temporary foreign body sensation was $16 \%$ in group A (tube kept for 3 months) and 12\% in group B (tube kept for 2-3 weeks).However there were no tube related complications noted [11].

In a study done by Anderson RL who placed the tube for 2 to 18 months depending upon the indication, reported tube related complications like lateral displacement of tube in $13.9 \%$, punctal erosion and nasal migration of tube in $11.6 \%$ each [14].

In our study also, nine (30\%) participants complained of foreign body sensation in eye, however lateral migration of tube with corneal erosion was seen in one patient only. Hence, we can observe that many patients have foreign body sensation with tube in normal position as well. Mimura M - In a single case where prolonged placement of a lacrimal silicone tube for 20 years was reported, they found granulation tissue formation due to inflammation in the lacrimal duct. It was treated by removal of the silicone tube and conservative medical treatment [15].

Gul Adam, et al., in their study of the effect of silicone tube implantation to the success rate of dacryocystorhinostomy surgery, found only one patient among 79 patients having tube related complication of silicone rod extrusion which was managed with the aid of an intranasal endoscope, and the silicone rod was retrieved to its previous position. No punctal erosion, corneal erosion, and granuloma formation were seen for following six months in postoperative period [12].

KB Anaur, in a case report of eight and nine years delay in tube removal following DCR surgery for bilateral congenital NLDO reported nasal mucosal infection with encrusting of tube on both sides and cheese wiring on one side. However after tube removal and management with antibiotics and steroids, there was complete recovery without any evidence of epiphora. 16 
Goel R, et al., in a prospective study of microbial growth following laser assisted DCR with silicon tubing found bacterial growth in $100 \%$ of cases and concluded that silicone intubation induced microbial growth can lead to failure of DCR if not treated with antibiotics [13].

The initial thought of tube related complications like punctal and canalicular erosion were significant in delayed tube removal can be dismissed with this study as well as previous studies $[11,16]$.

Fayers and Dolman in their study of DCR with tube versus no-tube reported complications of silicon stent like cheese-wiring of canaliculus and tube prolapse in $4 \%$ each, chronic irritation and stent incarceration in $2 \%$ of 152 patients who received intubation [8].

Unlu HH, et al., in the comparative study of endoscopic DCR with and without stent reported six patients in the intubation group (42.9\%) having granulation tissue at the rhinostomy site and four patients (28.6\%) complained of discomfort with silicon tube [17].

These findings in our study as well as other studies suggest that prolonged intubation with silicon rod have some complications but they are not grievous and are easily treatable.

\section{Conclusion}

The lacrimal system and the silicone tube are tolerant to prolonged intubation after DCR surgery when the tube had been placed properly with careful observation. Hence, prolonged intubation of nasolacrimal duct obstruction is safe in selected cases or in unavoidable circumstances like COVID lockdown.

\section{Ethics Approval and Consent to Participate}

The study was approved by the institutional review board of Tilganga Institute of Ophthalmology, Kathmandu, Nepal. Approval Reference Number: 01/2021.

\section{Human and Animal Rights}

No animals were used in this research. All human research procedures followed were in accordance with the ethical standards of the institutional committee and with the declaration of Helsinki.

\section{Conflict of Interest}

The authors declare no conflict of interest, financial or otherwise. 


\section{References}

1. Chandler PA. Dacryocystorhinostomy. Trans Am Ophthalmol Soc. 1936;34:240-63.

2. Bosniak S. Principles and practice of ophthalmic plastic and reconstructive surgery. $1^{\text {st }}$ Ed. Philadelphia: Saunders; 1996.784-96 p.

3. Yakopson VS, Flanagan JC, Ahn D, Luo BP. Dacryocystorhinostomy: History, evolution and future directions. Saudi J Ophthalmol. 2011;1;25(1):37-49.

4. Older JJ. Routine use of a silicone stent in a dacryocystorhinostomy. Ophthalmic Surg. 1982;13(11):911-5.

5. Gibbs DC. New probe for the intubation of lacrimal canaliculi with silicone rubber tubing. Br J Ophthalmol. 1967;51(3):198.

6. American Academy of Ophthalmology. List of urgent and emergent ophthalmic procedures 2020. [Last accessed on: Dec 10, 2021] https://www.aao.org/headline/list-of-urgent-emergent-ophthalmic-procedures

7. Ali MJ, Hegde R, Nair AG, Bajaj M, Betharia SS, Bhattacharjee KM, et al. All India Ophthalmological Society - Oculoplastics Association of India consensus statement on preferred practices in oculoplasty and lacrimal surgery during the COVID-19 pandemic. Indian J Ophthalmol. 2020;68(6):974-80.

8. Fayers T, Dolman PJ. Bicanalicular silicone stents in endonasal dacryocystorhinostomy: results of a randomized clinical trial. Ophthalmol. 2016;123(10):2255-9.

9. Saiju R, Morse LJ, Weinberg D, Shrestha MK, Ruit S. Prospective randomised comparison of external dacryocystorhinostomy with and without silicone intubation. Br J Ophthalmol. 2009;93(9):1220-2.

10. Lee MJ, Park J, Yang MK, Choi YJ, Kim N, Choung HK, et al. Long-term results of maintenance of lacrimal silicone stent in patients with functional epiphora after external dacryocystorhinostomy. Eye. 2020;34(4):66974.

11. Massoud OM, Elbakary MA, Shalaby OE, Hashish AA. Evaluation of the Role of Silicone Intubation in Noncomplicated External Dacryocystorhinostomy. Open Ophthalmol J. 2020;14(1):21-4.

12. Gül A, Duran M, Can E, Ozturk HE, Ariturk N. The effect of silicone tube intubation in external dacryocystorhinostomy. Acta Medica Anatolia. 2015;3(1):1.

13. Goel R, Nagpal S, Kamal S, Kumar S, Mishra B, Loomba PS. Study of microbial growth on silicone tubes after transcanalicular laser-assisted dacryocystorhinostomy and correlation with patency. Nepal J Ophthalmol. 2016;8(16):119-27.

14. Anderson RL, Edwards JJ. Indications, complications and results with silicone stents. Ophthalmol. 1979;86(8):1474-87.

15. Mimura M, Oku H, Ueki M, Sato B, Ikeda T. A case of neglected silicone tube in lacrimal duct for 20 years. Am J Ophthalmol Case Reports. 2018;11:41-4.

16. Anuar K Bin, Gendeh BS. Tube extrusion and cheese wiring five years post dacryocystorhinostomy. Philipp J Otolaryngol Neck Surg. 2011;26(2):25-7.

17. Unlu HH, Toprak B, Aslan A, Guler C. Comparison of surgical outcomes in primary endoscopic dacryocystorhinostomy with and without silicone intubation. Ann Otol Rhinol Laryngol. 2002;111(8):704-9.

Sthapit PR | Volume 2; Issue 3 (2021) | JOAR-2(3)-026 | Research Article 